\title{
Adamov's Alienation Effect: Showing the Absurdist Slant of the Epic Theatre Aesthetic
}

\author{
Nicholas Maurer, Clark Honors College*
}

\begin{abstract}
Epic Theatre and Absurdism could not be further apart. Epic Theatre was constructed in order to teach audiences morality, while Absurdism asserts that the world is deprived of morality and meaning. The contrast between styles can be seen by comparing the work of Bertolt Brecht to Samuel Beckett, figureheads of these two movements. Although these styles seem to originate from two separate schools of thought, they actually exist under the umbrella of modernism, and their connection is exemplified by the works of Arthur Adamov, who used Brechtian theory for his absurdist plays. Most notably, Adamov borrowed Brecht's alienation effect. In his plays Professor Taranne, Paolo Paoli, and Ping Pong, Adamov adapted Brecht's alienation effect in order to allow the audience to remove themselves from the exaggerated, absurd plot of the play. Instead of showing morality, this effect allows the plays to be more humorous than if an audience was to become invested in the onstage plight.
\end{abstract}

\section{INTRODUCTION}

In the world of the arts, as with many other parts of life, we are constantly borrowing and building off those who came before us. The story of Arthur Adamov's alienation effect exemplifies this. The end of the 19th century brought about a transformation of the theatrical aesthetic, which went from star-driven, melodramatic styles to the Naturalism and Realism aesthetics that mark the beginning of the modernism period. The playwrights and theatre artists of the Naturalism and Realism movements wanted to express truth onstage, by drawing the audience into the reality of life presented onstage. This period is the origin of the concept of the Fourth Wall, which refers to the audience looking onto the stage as if they were looking through a window pane. In response to his predecessors of the Realism and Naturalism movements, Bertolt Brecht created the aesthetic of Epic Theatre. At the crux of Brecht's theories is his Verfremdungseffekt, which is less than aptly translated by some scholars to "alienation effect". This quintessential component of Brecht's theories boils down to separating the audience from the play in order to invoke an objective response from the audience. Brecht often used this tool in his plays in order to teach the audience a moral lesson through the mistake of the characters onstage. When we think of Brecht and his work, critics and academics often return to the moral

* Nicholas J. Maurer is a Mathematics, Theatre Arts double major in the Robert D. Clark Honors College at the University of Oregon, focusing on playwrighting and theatrical design. He has recently been awarded the Very Little Theatre Memorial Scholarship as well as the Theatre Art Alumni Scholarship for his work academically and artistically in the theatre department. He has also recently presented at the 3 rd annual Climate Change and Indigenous Peoples Conference hosted at the University of Oregon. After college, he hopes to become a playwright or screenwriter. Please direct correspondence to nicholas.j.maurer@gmail.com. 
questions and lessons that Brecht centered his plays around. These strongly didactic motives blind us from acknowledging the humor present in Brecht's works or in other plays that use the alienation concept.

Absurdism is an theatrical aesthetic that rose in the aftermath of World War II. The philosophy of absurdism centers around the concept that life is meaningless and the search for meaning is also inherently meaningless. For the theatrical aesthetic, this lead to numerous comedic plays, which heighten simplistic plotlines to extraordinary proportions. One of the most famous examples is Samuel Beckett's Waiting for Godot, a full length play where two friends try to pass the time waiting on a person named Godot, who never comes. Beckett labels this play a Tragicomedy, referring to the humor we can take in the depressing boredom the main characters must fend off. Although Absurdism and Epic Theatre have little in common, the Russian playwright Arthur Adamov borrowed tools from both aesthetics in his fusion of the genres that make up his own work.

When examining his plays, it becomes clear the Adamov's main tool for humor is Brecht's alienation effect. Brecht used the effect for his didactic objectives. However, it is a common misunderstanding that this distancing removes the emotional weight of the action onstage (Oliver 230). Instead, when used adeptly, the alienation effect heightens the emotional response of the audience. This can be exemplified through the work of Arthur Adamov, a lesserknown contemporary playwright of Brecht, who bridged the Epic Theatre and Absurdist styles by adapting this alienation effect to highlight the absurdism within the plots, the characters, and the tones of the plays. This paper focuses on how Adamov uses his adapted alienation effect in three plays, namely Professor Taranne, Paolo Paoli, and Ping Pong. These three plays represent the breadth of situations and devices that Adamov created in order to alienate the audience. Through his three plays, Professor Taranne, Paolo Paoli, and Ping Pong, Arthur Adamov adapts Brecht's concept of the Verfremdungseffekt (alienation effect) in order to prevent the audience's natural empathetic tendencies and bar them from being drawn into a frivolous plot. In these three plays, Adamov adapted Brecht's theory by historicizing the plot, revealing plot points, and incorporating projections and numerous scenic changes in order to reveal to the audience the ridiculousness of the plight of the characters and the plot Adamov had constructed.

Drawing upon the practices of his predecessor Pisactor, Brecht developed alienation effect as a method of educating the audience (Brecht, "On Experimental Theatre" 15). Brecht described alienation as "the process of [historicizing], of presenting events and persons as historical, therefore as ephemeral” (Brecht, "On Experimental Theatre” 14). Brecht's most common method of historicizing was setting his plays in a distant time and place, physically separating the social boundaries of the world of the play from the boundaries in reality. For example, Brecht sets The Good Person of Szechuan in China and The Threepenny Opera in nineteenth century Victorian England. This removal of place separates the audience from a personal connection to the time and place of the play. His hope was that "by presenting a situation in a striking and unaccustomed light, [it would] draw the audience's critical attention to the social forces which determine human destiny" (Steer 639). By drawing out the audience's attention, Brecht forces them to actively, rather than passively, engage in the play. Active 
attention incites the audience's continuous judgment of the characters' actions as well as the situations in which the characters find themselves. It also allows the audience to compare their own lives to the experiences onstage from a more rational, rather than emotional, perspective. Therefore "to 'alienate' does not mean... to separate the actor from the character or the stage from the audience" (Dort and Ostergren 31). Rather, the alienation effect "removes the stamp of familiarity from phenomena capable of being modified by society" (Dort and Ostergren 30). This is not to say that the emotional connection between the audience and the action is entirely removed. It is simply becomes sympathy instead of empathy, which allows the audience to feel for the action onstage without losing focus on the message being communicated. Alienation distances the audience from time and place, but not from human emotion and moral obligation.

\section{ALIENATION AND ADAMOV}

Brecht utilizes this alienation in order to force the audience into an objective position, through which they can have visceral reactions to characters part of an entirely different world. In order to achieve this state of being, the "stage and auditorium must be purged of everything 'magical' and that no 'hypnotic tensions' should be set up" (Brecht 136). This purging is usually achieved by stripping the stage of anything extraneous. Sets need not be minimal, but they cannot be elaborate and should not hide the structure of the theater. Lighting fixtures can be in sight of the audience. Costumes do not need to represent any particular period; they just have to be larger than life. Epic Theatre abandons the concept of the unity of design, asserting a cacophony of elements, which remind the audience of their presence in the theater (Brecht, "On Experimental Theatre" 15-16). All of these small details remind the audience that they are sitting in a theater watching a play, so that their mind does not become hypnotized by the action. Through the rejection of orthodox theatrical conventions, Brecht's Epic Theatre "intended purely to show the world in such a way that it becomes manageable" (Brecht, Brecht on Theatre 140). With a "manageable" world-view, the audience can break down the plot and characters into their fundamental moral components and learn from their faults onstage. Brecht's rejection of hypnosis should not be convoluted with a rejection of emotional connection. Brecht wrote that "we need a type of theatre which not only releases the feelings, insights, and impulses possible within the particular historical field of human relations in which the action takes place, but employs and encourages those thoughts and feelings which help transform the field itself" (Brecht on Theatre 190). The constant interruption of the viewing experience should not remove the emotional reactions of the audiences, only distance their empathetic connections and their submersion in the world. The end goal of the alienation effect is to emphasize the spectacle, the morality, and the objective perception of the audience in order to have a didactic production.

Adamov adapted this method of alienation for his own work. William Oliver suggests, "alienation in absurdist drama is... an effect incompatible with the play itself" (Oliver 230). At first thought, alienation and absurdism should conflict, since absurdism is dependent on the lack of meaning. Without the possibility of a didactic production, Brecht's alienation effect is rendered useless. Yet Adamov draws upon alienation techniques in order to augment the absurdism of the situation for his audience. For the characters in these plays, butterfly hunting and conquering pinball machines have progressed to life or death situations; therefore, the 
alienation effect is necessary in order to rid the audience of any empathetic feelings for the ridiculous dilemmas of the characters, thus producing humor. "Adamov seems to have tried to avoid the complete alienation of the spectator" (Dietemann 53). Instead of constantly reminding the audience of the theatrical setting, throughout his plays Adamov allows the audience to have reoccurring epiphanies of the theatrical nature of the play. Through his adaptation of Brecht's alienation effect, Adamov crafted a form of separation between the audience and the stage that best highlights the absurdism in his plays.

\section{PROFESSOR TARANNE}

In Professor Taranne, Adamov achieves his tragic farce by isolating the professor, and thereby alienating the audience. Tragically, Professor Taranne is mostly forgotten by nearly every character with whom he comes in contact. At one point a fellow professor, known only as Smart Woman believes she recognizes the professor. At the point we are about to learn Taranne is, we discover that Smart Woman has mistaken him for someone else. By refusing to share Taranne's identity with the audience, Adamov shows us Taranne's "self-imposed image... as a destroyer of true self" (McCann 40). This continual questioning of the truth or deceit behind Tarenne's identity interrupts our understanding of him. In a moment, the audience is simultaneously pushing him onward as well as solving his identity mystery. This multidimensional pull of Taranne is a form of Adamov's alienation effect. By the end of the play, Taranne begins to strip off his clothes, the crime he was charged with and which he denied in the opening scene (Adamov, Two Plays 30). This completes our mistrust of Taranne, as the play ends without revealing the truths and falsities of what Professor Taranne has told the police, and subsequently the audience. Besides being an element of alienation from the character, this moment at the end of the play is absurd and humorous, in what can otherwise be described as Tarenne's nightmare. If the audience was emotionally drawn into the play, these final moments might be misconstrued for the tragic message of Taranne becoming the man society thinks he is, which does not coincide with the absurd philosophy. From an alienating point of view, the audience instead understands the psychotic nature of Taranne, which reveals the humor within the confusion of the world that just passed before them.

In addition to the isolation of Professor Taranne, Adamov relies heavily on the authorities' and audience's active judgment of Professor Taranne as another alienation element stemming from Brechtian practices. Twice in this play, Taranne is accused by police and stripped of his liberty in the process (Adamov, Two Plays). Since these actions happen immediately at the top of each scene, until the final moment the audience is asked to be a jury of peers in this play-judging whether or not Taranne is a criminal based upon circumstantial evidence. By asking the audience to fulfill this role of judgment in the story, the audience must immediately call upon their objectivity, forcing them to distance themselves from Professor Taranne and the plot. This call to action is typical in Brecht's work and is borrowed here by Adamov to achieve an alienation effect. 


\section{PAOLO PAOLI}

In Adamov's play Paolo Paoli, Adamov alienates the audience by historicizing the action. Paolo Paoli is set in the years prior to World War I, starting in 1900 and ending right before the war in August of 1914 (Adamov, Paolo Paoli). Since Adamov wrote this play in the 1950s, he has distanced his French audience in time, but not in place. The audience is aware of the aggressive political actions leading to war, yet the characters are more concerned with the acquiring and trading of butterflies than politics, even when Czar Nicholas II writes to Wilhelm II stating that Wilhelm "may be obliged to mobilize" (Adamov, Paolo Paoli 116). Europe was about enter the bloodiest war it had ever seen, which was similar to the war that Europe had recently lived through at the time Paolo Paoli premiered, but these characters are in conflict over butterflies. By setting this play in this historical context, the major conflict instantly becomes a trifle, thus the plot and the characters are simply absurd in comparison. This absurdism would not be possible without this historicization. Without the context, absurdism within the play would not exist, or at least not be as potent. Adamov establishes this historical context by projecting the year and a few headlines and quotes from different sources in that year. Accentuation of the projections in combination with the play is critical to the establishment of Adamov's alienation effect.

The second prominent method Adamov uses to alienate his audience in Paolo Paoli is the multitude of setting changes that occur through the play. The play swiftly moves from Paolo's residence to Hulot's residence to Robert's residence and everywhere else in between (Adamov, Paolo Paoli). These rapid changes of location reminds the audience that the world onstage is a created world rather than allowing them to submerse themselves inside a single location or a one-piece set. The movement of place allows audiences personal insight into each character, as they visit each residence. After bouncing between the residences of the Abbe, Paolo, and Hulot, we finally come to Robert's domicile in the Act II, which is described as "whitewashed walls. A small iron bedstead, sheets of paper and newspapers are strewn about the floor" (Adamov, Paolo Paoli 96). This contrasts heavily with the lavish locations the audience has been visiting throughout the play, which only augments the disparity between the classes and the abuse of the lower classes by the upper classes in this period of French society. Alienating this location, and thus the characters foreign to this location, creates a plot that critiques the problems among the upper class and comments on the inflated trifles through which the well-off "suffer".

\section{PING PONG}

Adamov uses some similar methods of alienation in his play Ping Pong. First and foremost, Adamov historicizes the play, although he uses a different method than in Paolo Paoli. Rather than setting the play in a certain place and time period, Adamov historicizes the play by extending the time frame of the play to cover most of the entire lives of the two main characters, Arthur and Victor. The play starts with both of these characters as students in university (in their early twenties) and ends with these two as "white-haired septuagenarians" (Adamov, Two Plays 120). This fifty-plus-year span of the plot creates a false sense of history that has passed 
during their lifetimes as well as the play, without citing any particular dates (Adamov, Two Plays). Every time the play leaps forward in time, the audience must disconnect from the world in order to recognize the new age of all the characters and the time that has passed from the last scene. This interruption alienates the audience in order to follow the progression of the pinball addiction through Arthur and Victor's lives.

In addition to historicizing the plot, Adamov also makes use of a number of major scenic shifts in Ping Pong, rarely revisiting the same location twice. Mrs. Duranty, who begins the play owning and operating a small bar, is constantly trading her business for another operation, as she moves to a bathhouse, then to a dance studio, then to a public park, before her final scene outside an arcade (Adamov, Two Plays). Similar to Paolo Paoli, these rapid scenic changes also remind the audience of their presence in a theater, alienating them from a stable sense of the world of the play. This time, Adamov uses these changes to augment the passage of time. The audience would not assume that Mrs. Duranty has a new business everyday, thus we can guess that a larger amount of time in between one business and the next. There could be more design choices that also include this passage of time, notably in the costumes of the play, yet these changes are not documented in the text (Adamov, Two Plays).

In Ping Pong, Adamov centers the conflict on a trivial matter, which Arthur and Victor's debate over what bells and whistles make up the perfect pinball machine. The play is about the pinball industry, referred to simply as the "Organization", and the attempted mastery of the pinball machines, referred to as the "machine" (Adamov, Two Plays 40-1). By heightening a trivial matter while alienating the audience, Adamov succeeds in augmenting the absurdity of the plot and characters within the play. When reading or seeing the play, we can recognize that much of the humor "results from the distance between the grandiose effort, constant concern, flights of poetry and persistent energy of the principal characters and the relative triviality of the object of their dedication" (McCann 79). In dire pursuit of the perfection of the game, Arthur and Victor almost completely sacrifice the things of value within their own lives, such as their education, their career, and even their relationship. This destructively obsessive pursuit of a trivial matter is a didactic and humorous component to Adamov's absurd play. Therefore, Ping Pong highlights the importance of the alienation effect in absurdist drama, contradicting William Oliver's statement that "alienation in absurdist drama is... an effect incompatible with the play itself" (Oliver 230). Instead, the alienation effect can be used to draw out the humor in theatre. The machine is "a concrete object which dominates the protagonists' existence, corrupts their vision, informs their language, and invalidates their energies" (McCann 80). The machines rip apart every character in this play. Even Roger, the only character without an obsession of the machines, is destroyed through his relationships with others who are infected. This play allows characters to destroy their own liberty because of their relationship with these machines. The audience follows the tragic comedy as the characters humorously fall into the trap of a meaningless, childish addiction.

Of the three plays discussed, Ping Pong draws the most upon Brecht's alienation effect. Along with the other examples of alienation in Ping Pong that have already been cited, which can be considered methods duplicated in his other works, Adamov presents several moments in 
this play that serve to completely remove the characters from the world they inhabit. In these moments the curtain is down while Arthur and Victor are walking in front of the curtain, lit solely by follow-spots. It is in these moments that Adamov indicates a major time-shift as well as reveals future plot points, such as the impending rejection of their pinball proposal to $\mathrm{Mr}$. Constantine. Before they present their idea to Mr. Constantine, Victors tell Arthur, "We had no choice. It was a case of now or never. I admit, it is a rather an irrational step to take, but I couldn't resist it" (Adamov, Two Plays 103). Adamov uses the past tense when referring to a presentation that has not happened for the audience, thus informing the audience of what is to follow onstage. The audience is alerted that Mr. Constantine will reject the proposal before the scene begins, thus they can judge the merits of the proposal and the obsession of the characters rather than rooting for the characters' success. Yet, rather than judging the proposal for a moral lesson, the audience judges the proposal for how frivolous and absurd these changes would be since they only add more bells and whistles to the machine.

Adamov's alienation of the audience throughout Ping Pong provokes a more prevalent emotional response than simply humor. By the end of the play Arthur and Victor's obsession over the machine transforms into an obsession over Ping Pong, the title game of the play. While arguing what the Ping Pong rules should be, Victor suddenly dies. This abrupt death ends the decades of debates Victor and Arthur shared in order to perfect something as ridiculous as a pinball machine, thus "we are left with the beautiful unresolved ambiguity of knowing who is the 'victor;" Victor who dies and escapes, or Arthur who lives on, but who is now old and alone, robbed of the one meaningful factor in his life, his friendship with Victor" (McCann 83). It is in this moment that tragedy strikes Arthur. Since the alienated audience has judged the quarrels induced by the machine between the two companions from the beginning, this moment evokes a more empathetic reaction to the end of the play. It is only after the audience has judged Victor and Arthur's trivial pursuit throughout the entire play that this moment evokes the strongest possible feeling of empathy because of the life and time that had been wasted. While Brecht and others have traditionally used the alienation effect as a didactic device, this is an example of the alienation effect being used as an emotionally evocative tool.

\section{CONCLUSION}

In his three plays Professor Taranne, Paolo Paoli, and Ping Pong, Adamov adapts Brecht's alienation effect (used first in his Epic Theatre) in order to apply it to the new wave of absurdism. Adamov adapted Brecht's theory in order to communicate humor that would have otherwise gone unnoticed within his plays. In addition, this adapted alienation effect was used to augment the absurdity as well as the humor of the dramas. It is likely that Adamov's other plays (which could not be located in English translations) use similar devices, which bridge the theatrical ideologies of Epic Theatre and Theatre of the Absurd. In the end, this analysis demonstrates the breadth of reactions that alienation effect can inspire. The common myth is that Epic Theatre and the alienation effect create an emotionless response from the audience, but on the contrary, the alienation effect can be used to evoke a wide range of emotions in a disengaged audience. 


\section{APPENDIX}

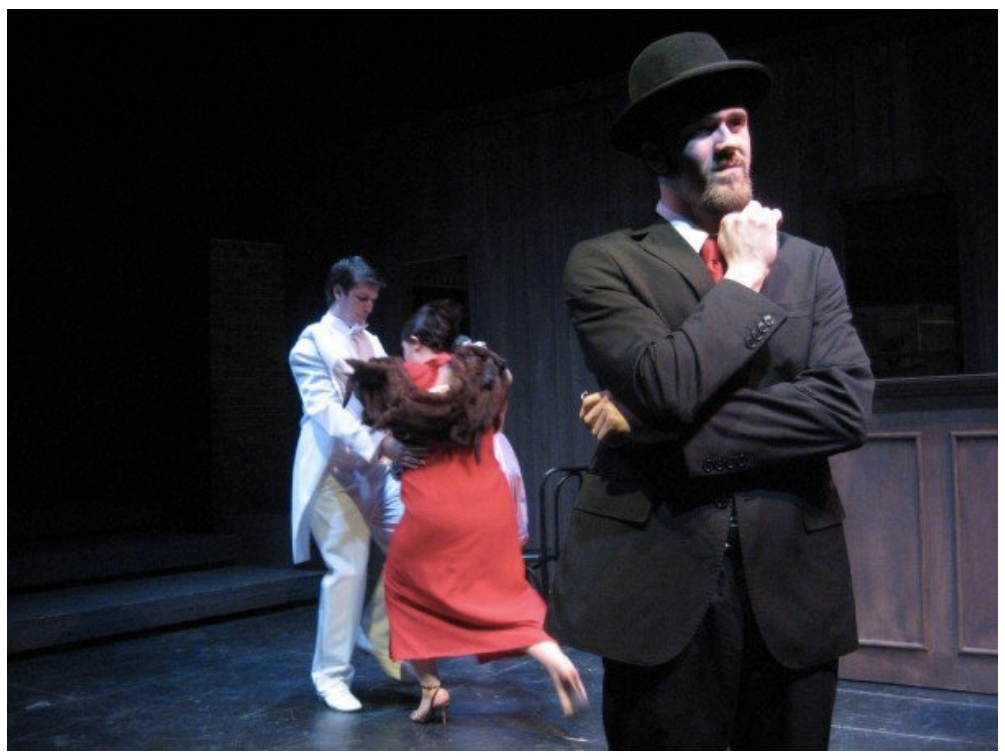

Figure 1. A contemporary production of Adamov's Professor Taranne, with Christian Grunnah playing the title character. Professor Taranne is separated from the other two characters through space, light, and costume. Taranne is pulled to the front of the stage and is left isolated at several instances during the play.

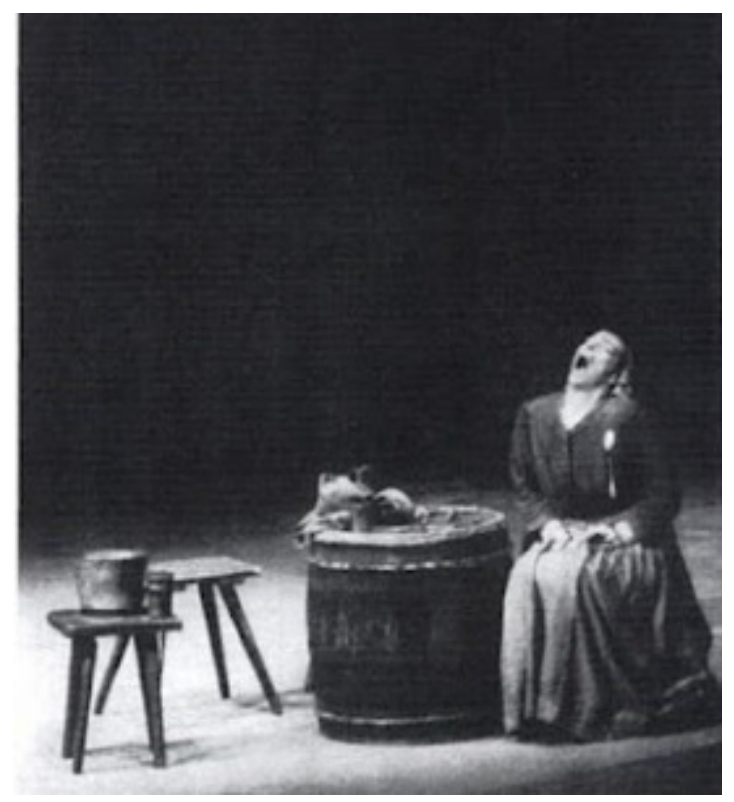

Figure 2. Helene Weigel playing the title character in Brecht's Mother Courage. This photo is used as a defining image of the alienation effect. Weigel mimes the silent scream, lamenting the loss of her sons. The audience cannot hear the scream they expect to hear from the character in this moment. This surprising silence separates the audience from the world of the play. (Alfrun) 


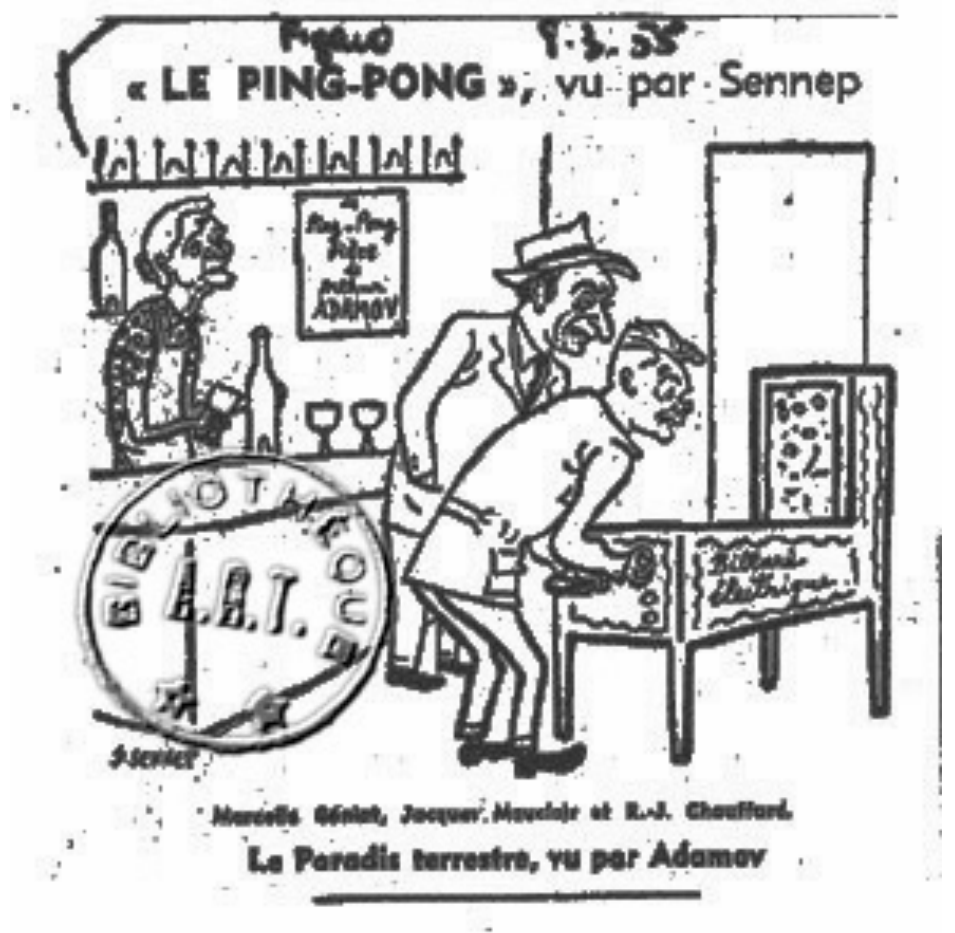

Figure 3. A drawing depicting the opening scene of Ping Pong. Arthur and Victor are captured by the machine, while Mrs. Duranty cleans glasses. All three characters in this image have their eyes focused on the machine. (Sennep)

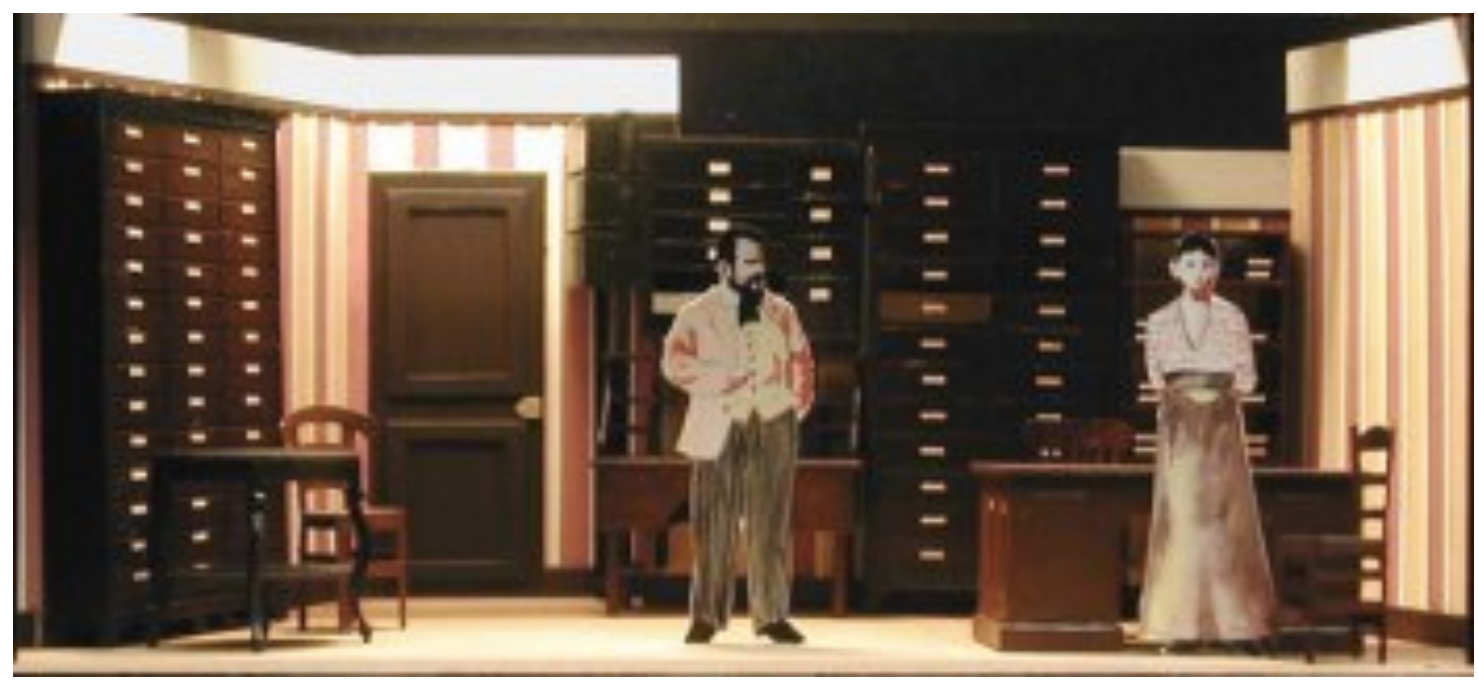

Figure 4. A set design by Rene Allio of Roger Planchon's 1958 production of Paolo Paoli in Paris. Paolo and Rose are shown having a conversation in Paolo's study. Disparity between Paolo, the businessman, and Rose, the servant, is shown through costuming. (Douaire, et al.) 


\section{REFERENCES}

Adamov, Arthur. Paolo Paoli. Trans. Geoffrey Brereton. London: John Calder LTD, 1959. Print.

---. Two Plays: Professor Taranne and Ping Pong. Trans. Peter Meyer and Derek Prouse. London: John Calder LTD, 1962. Print.

Alfrun. The Silent Scream. Masks, Mime, Puppets and Physical Theatre, Wordpress, 25 Jan. 2013. Web. 3 June 2015.

Brecht, Bertolt. Brecht on Theatre: The Development of an Aesthetic. Trans. John Willet. New York: Hill and Wang, 1964. Print.

---. “On the Experimental Theatre.” Trans. Carl Richard Mueller. The Tulane Drama Review 6.1 (1961): 2-17. Electronic.

Dort, Bernard and Ostergren, Christopher. "Epic Form in Brecht's Theatre” Theater 1.2 (1968): 24-34. Electronic.

Douaire, Martin, et al. Scene from Arthur Adamov's Paolo Paoli directed by Roger Planchon, set by René Allio, at Le Théâtre du Vieux-Colombier, Paris, 1958. Photograph. Set Design:1950s, The Red List. Web. 3 June 2015.

McCann, John J. The Theater of Arthur Adamov. Chapel Hill: University of North Carolina at Chapel Hill, 1975. Print.

Oliver, William I. "Between Absurdity and the Playwright." Educational Theatre Journal 15·3 (1963): pp. 224-235. Electronic.

Sennep. The Ping Pong. 1958. Association of A.R.T. Theatre Board, Paris. Web. 3 June 2015.

Steer, W. A. J. “Brecht's Epic Theatre: Theory and Practice” Modern Humanities Research Association 63.3 (1968): pp. 636-649. Electronic. 